\title{
Citation:
}

Puthillam, A. Karandikar, S., Kapoor, H. \& Parekh, A. (in press). Gratitude Blindness: How does the Dark Triad experience gratitude? Personality and Individual Differences.

\section{Gratitude Blindness: How does the Dark Triad experience gratitude?}

Arathy Puthillam, Sampada Karandikar, Hansika Kapoor, Aneree Parekh

Monk Prayogshala

Author Note

This manuscript has been accepted for publication. However, the final version of the manuscript will include slight modifications from the current version.

Arathy Puthillam (AR) ${ }^{1}$, Senior Research Assistant, Department of Psychology, Monk Prayogshala; Aneree Parekh (AP), Research Assistant, Department of Psychology, Monk Prayogshala; Sampada Karandikar (SK), Research Author, Department of Psychology, Monk Prayogshala; Hansika Kapoor (HK), Research Author, Department of Psychology, Monk Prayogshala.

\footnotetext{
${ }^{1} \mathrm{AR}$ and AP were contributed to study conceptualization and data collection. AR contributed to data preparation. AR and SK contributed to data analysis. AR, AP, SK, and HK contributed to report writing and editing. AR, SK, and HK contributed to revision based on reviewer's comments.
} 
Correspondence concerning this article should be addressed to Arathy Puthillam, Department of Psychology, Monk Prayogshala (Sec 8), 4114, C Wing, Oberoi Garden Estates, Powai, Mumbai 400072, Maharashtra, India.

E-mail: ar@monkprayogshala.in

The study has been preregistered in the Open Science Foundation repository and can be retrieved from osf.io/s4jq3.

The present study was not funded by any particular grant or organization.

\section{Author CRediT statement}

Arathy Puthillam: Conceptualization, Methodology, Data Curation, Formal Analysis, Investigation, Writing- Original Draft Preparation, Review \& Editing

Sampada Karandikar: Validation, Supervision, Writing- Original Draft Preparation, Review \& Editing

Hansika Kapoor: Supervision, Writing- Original Draft Preparation, Review \& Editing Aneree Parekh: Conceptualization, Methodology, Writing- Original Draft Preparation 


\section{Abstract}

2 Gratitude promotes prosociality and long-term reciprocal relationships. The Dark Triad is 3 associated with maladaptive interactions in their social and interpersonal relationships. The

4 present study aimed at understanding whether these individuals experience gratitude at state

5 and trait levels, when presented with situations that differentially benefit them. The Dark

6 Triad, specifically psychopathy and Machiavellianism, is negatively associated with trait

7 gratitude. In situations where others are uncooperative towards them, individuals with Dark

8 Triad traits, specifically Machiavellianism and narcissism, report poorer state gratitude.

9 Implications are discussed, particularly in light of the Dark Triad as a defector personality

10 hindering reciprocal altruism.

Keywords: Gratitude; Dark Triad; Reciprocal Altruism; Psychopathy;

12 Machiavellianism; Narcissism 


\section{Gratitude Blindness: How the Dark Triad Experiences Gratitude}

Gratitude indicates a positive, appreciative, people-oriented worldview. It is purported to promote prosociality through moral functions (McCullough et al., 2002), thereby highlighting to its recipients that benefits have been accrued, motivating prosociality, and encouraging continued generosity. Gratitude initiates, maintains, and develops social bonds (McCullough et al., 2002). Prosociality, via gratitude, also helps in enhancing social ties and resources (Zhao et al., 2016).

Emotions like gratitude are conceptualized at state and trait levels. State gratitude (SG) occurs after a person has been helped and motivates the reciprocation of aid (Bartlett \& DeSteno, 2006). Trait gratitude (TG) has unique associations with other prosocial traits (e.g., empathy; Mccullough et al., 2002). If the two are indeed linked, how does prosociality, through gratitude, function in individuals with more agentic personalities? This relationship is unclear among those who are likely to be dispositionally uncooperative (Jonason, Li, et al., 2010).

\section{The Dark Triad and Life History Theory}

Subclinical traits of psychopathy, Machiavellianism, and narcissism (the Dark Triad or DT; Paulhus \& Williams, 2002) are characterized by an agentic social style (Jonason, Li, et al., 2010), implying tendencies to manipulate and exploit others for their own gain. The Dark Triad is typically associated with a fast-life strategy, as explained by the life history theory (e.g., Jonason et al., 2017). Such a strategy embodies impulsive, individualistic, and competitive behaviors. Each trait uses different tactics of social influence and manipulation. Although psychopathy is consistently linked to fast-life strategy, Machiavellianism is not. Narcissism is associated with slow-life strategy; they usually evaluate long-term ramifications of their actions (e.g., Jonason et al., 2017). The DT is also associated with a 
cheater social strategy (Jonason \& Webster, 2012), further indicative of interpersonal exploitativeness and a fast life (Jonason, Koenig, et al., 2010).

Those high on DT traits see others as having lower agency (i.e., as having traits that benefit them; Jonason, Li, et al., 2010). For example, psychopathy is characterized by low regard for others, extreme disagreeableness, irresponsibility, and low levels of empathy (Paulhus \& Williams, 2002). DT are also maladaptive in their selection of social bonds (see Jonason \& Schmitt, 2012). For instance, those with high Machiavellianism facilitate their cheater strategy by choosing easily exploitable friends (Jonason \& Schmitt, 2012).

Furthermore, DT perceive their friends to frequently emotionally manipulate them (Abell et al., 2016), implying that they may not be able to or are not motivated to assess others' prosociality.

\section{The Present Study}

Thus, in their interpersonal relationships, those high on DT traits perceive and interact in fundamentally maladaptive ways. It, therefore, remains unclear whether and how these individuals experience gratitude. This study aims to assess the experiences of such persons in the face of prosocial behaviors, via gratitude. Given the function of gratitude in reciprocity and the tendency of those with high DT traits to be agentic in prosocial scenarios, this study postulates that high DT would express poorer trait gratitude. Next, when the benefit proffered to them is high versus low, we ask how high DT expresses state gratitude. However, the traits are often susceptible to social desirability effects (Kowalski et al., 2018), which is controlled for in the current study. To the best of our knowledge, this would be the first exploration of the positive emotion of gratitude within the darker personalities.

Thus, we hypothesize the following: 
60

61

H1: $\mathrm{DT}^{2}$ negatively predicts trait gratitude.

H2A: For high-benefit situations, DT predicts state gratitude.

H2B: For low-benefit situations, DT predicts state gratitude.

\section{Method}

\section{Participants}

The present manuscript reports specific findings from a larger preregistered study. ${ }^{3}$

With $a=.05$, a power of .90 , and an effect size of $.08,584$ participants were required. The sample comprised 679 participants (279 Indians, 317 Americans, and 83 belonging to 40 other countries; women $=514)$ above 18 years of age $\left(M_{\text {Age }}=23.37\right.$ years, $S D=8.04 ;$ Range $=18-68$ years). Online and social media sampling, multiple-site entry, and snowball sampling were used to collect data. This study has been approved by the Institutional Review Board of Monk Prayogshala (\#023-018).

\section{Measures}

The Short Dark Triad (SD3; Jones \& Paulhus, 2013). ${ }^{4}$ Twenty-seven items $(\alpha=.81)$ were used to measure the Dark Triad traits. Nine items each measure Machiavellianism $(\alpha=$ .76), narcissism $(\alpha=.50)$, and psychopathy $(\alpha=.71)$.

The Gratitude Questionnaire-Six Item Form (GQ-6; McCullough et al., 2002).

This six-item instrument $(\alpha=.78)$ measures trait gratitude.

${ }^{2}$ Composite DT will be assessed along with all three sub-components.

${ }^{3}$ Data, materials, and analysis code are also included in the repository.

${ }^{4}$ Confirmatory Factor Analysis and Measurement Invariance were conducted for each of the scales and have been included in the Supplementary Materials (Appendices A, B, and C). 
Vignettes measuring state gratitude (Wood et al., 2008). Participants were

randomly assigned to read either a set of three vignettes depicting situations with low (Group

A) or high benefits (Group B), measured in terms of value, genuine helpfulness, and cost.

Each vignette detailed a situation in which the participant had been helped by another person.

Based on these, participants reported state gratitude $(\alpha=.73$; Range $=3-18$; Appendix D).

The Balanced Inventory of Desirable Responding Short Form (BIDR-16; Hart et al., 2015). This scale comprises a 16-item social desirability measure $(\alpha=.75)$, incorporating Self-Deceptive Enhancement (SDE; $\alpha=.67$ ) and Impression Management (IM; $\alpha=.69$ ).

\section{Results}

Table 1 displays descriptive statistics and zero-order correlations. Hierarchical regressions were conducted, controlling for age, sex, ${ }^{5}$ nationality, ${ }^{6}$ and social desirability. Composite DT $\left(b=-.10, \mathrm{SE}=.02, \mathrm{R}^{2}=.14, F(1,673)=31.13, p<.001\right)$, Machiavellianism $\left(b=-.17, \mathrm{SE}=.04, \mathrm{R}^{2}=.13, F(1,673)=20.58, p<.001\right)$, and psychopathy $(b=-.35, \mathrm{SE}=$ $\left..04, \mathrm{R}^{2}=.19, F(1,673)=74.69, p<.001\right)$ negatively predicted $\mathrm{TG}$; the effect of narcissism on TG was small and not significant $(b=.03, \mathrm{SE}=.05, \mathrm{~ns} ; \mathrm{H} 1)$.

Next, we assessed whether DT predicts SG, given high (H2A) and low (H2B) benefits, controlling for TG. When the situation involved objectively low benefit, DT did not predict $\mathrm{SG}\left(b=.02, \mathrm{SE}=.01, \mathrm{R}^{2}=.05, F(1,445)=1.67, \mathrm{~ns}\right)$. This was also true of its subcomponents $\left(b \mathrm{~s}=.01\right.$ to $.04, \mathrm{SE}=.02$ to $.03, \mathrm{R}^{2}=.05$ to $.06, F(1,445)=.21$ to $\left.1.54, \mathrm{~ns}\right)$.

\footnotetext{
${ }^{5}$ Sex was coded as $1=$ Women, $2=$ Men, $3=$ Other

${ }^{6}$ Nationality was coded as $1=$ USA, $2=$ Indians, $3=$ Other
} 
97

98

99

However, in high benefits situations, psychopathy $\left(b=-.06, \mathrm{SE}=.02, \mathrm{R}^{2}=.20\right.$, $F(1,220)=7.90, p=.005)$ and narcissism $\left(b=-.05, \mathrm{SE}=.02, \mathrm{R}^{2}=.19, F(1,220)=5.35, p=\right.$ $.02)$ predicted SG, but DT $\left(b=-.01, \mathrm{SE}=.01, \mathrm{R}^{2}=.18, F(1,220)=2.21, \mathrm{~ns}\right)$ and Machiavellianism $\left(b=.02, \mathrm{SE}=.02, \mathrm{R}^{2}=.17, F(1,220)=1.34, \mathrm{~ns}\right)$ did not.

\section{Discussion}

We examined how individuals with high DT experience gratitude. Those with high DT, especially psychopathy and Machiavellianism, reported lower TG. Those higher on psychopathy and narcissism experienced lesser SG when others acted prosocially.

TG is linked to prosociality (McCullough et al., 2001). Higher DT is linked to lesser prosociality (Hilbig et al., 2014), and more exploitativeness and competitiveness (Jonason \& Schmitt, 2012). Accordingly, we found that individuals with higher DT traits, particularly psychopathy and Machiavellianism, experienced lower TG. Conversely, the "brighter" of the DT, narcissism (Rauthmann \& Kolar, 2013) did not affect TG. Those with high narcissism experience low communion, thereby avoiding gratitude, the costly emotion associated with forming close bonds and prosociality. Their characteristic sense of entitlement may also belie this non-expression.

Next, in situations involving low benefits, neither DT, nor its components influenced SG. DT and Machiavellianism did not affect SG in high benefit situations; however, psychopathy and narcissism negatively predicted SG. Those with higher Machiavellianism are less impulsive and more calculating (Jones \& Paulhus, 2013), and use charm as a social influence (Jonason \& Webster, 2012), perhaps explaining why they do not report low SG. Those with psychopathic traits are comparatively colder, more aggressive, and may rely on 
hardball tactics of social influence (Jonason \& Webster, 2012), which may be why they do not emphasize prosocial emotions such as gratitude. They may be more universal in their social influence tactics, utilizing singular coercive tactics (Jonason \& Webster, 2012), without paying attention to contextual cues about prosociality. Narcissism is associated with prosocial values, a slow life strategy, and is often brighter of the DT traits (Jonason et al., 2017). Given that narcissism is not linked to TG, but is negatively linked to SG in highbenefits situations implies that like those with higher psychopathy, they might not use contextual cues when engaging in prosocial situations.

To the best of our knowledge, the present study was the first to add to extant literature about those who are dispositionally likely to be uncooperative (DT) in reciprocal situations. For those with high DT, the poorer expression of gratitude might impede their ability or motivation to engage in long-term reciprocal relationships. Further, DT differentially experiencing gratitude in situations where others engage in costly behaviors is a worthwhile finding, further shedding light on the exploitative behaviors that are at the crux of these traits (Kajonius et al., 2016).

The study has implications in understanding reciprocal altruism and cooperation. Future research can study this link between DT, gratitude, and cooperation through economic games. Our study has practical implications, given that DT is linked to numerous interpersonal situations, such as leadership (e.g., Furtner et al., 2017) and intimate partner violence (Kiire, 2017).

Future studies can address some current limitations. First, we relied on self-report measures of gratitude. However, McCullough et al. (2002) argue that the GQ-6 is correlated with peer reports. Second, the internal consistency of the narcissism measure was less than adequate, indicating measurement issues. Future research can replicate this study using other 
measures of narcissism and DT in general, including measures acknowledging its

multidimensionality (Miller et al., 2019). Third, a ceiling effect was observed in the measure of SG (Supplementary Figure 1). In sum, DT, specifically psychopathy and

Machiavellianism, negatively predicted TG. DT is not associated with SG if the situation is not beneficial. When the situation is beneficial, however, those higher on psychopathy and narcissism experience gratitude, but of a lower magnitude, compared to low scorers.

\section{References}

Abell,L.,Brewer,G.,Qualter, P.,\& Austin,E.(2016). Machiavellianism, emotional manipulation, and friendship functions in women's friendships.Personality and Individual Differences,88,108-113.doi:j.paid.2015.09.001

Bartlett,M.Y.,\& DeSteno,D.(2006). Gratitude and prosocial behavior: Helping when it costs you. Psychological Science,17,319-325.doi:10.1111/j.1467-9280.2006.01705.x

Furtner,M.R.,Maran,T.,\& Rauthmann,J.F.(2017). Dark leadership: The role of leaders’ dark triad personality traits. In M.G.Clark\&C.W.Gruber (Eds.), Leader Development Deconstructed, 75-99. Springer International Publishing.doi:978-3-319-64740-1_4 Hart,C.M.,Ritchie,T.D.,Hepper,E.G.,\&Gebauer,J.E.(2015). The Balanced Inventory of Desirable Responding Short Form (BIDR-16): SAGE Open.doi:10.1177/2158244015621113 Hilbig,B.E.,Glöckner,A.,\&Zettler,I.(2014). Personality and prosocial behavior: Linking basic traits and social value orientations. Journal of Personality and Social Psychology, 107, 529539.doi:10.1037/a0036074

Jonason,P.K.,Foster,J.D.,Egorova,M.S.,Parshikova,O.,Csathó,Á.,Oshio,A.,\&Gouveia,V.V.(2 017). The dark triad traits from a life history perspective in six countries. Frontiers in Psychology,8.doi:10.3389/fpsyg.2017.01476 
167

168

169

170

171

172

173

174

175

176

177

178

179

180

181

182

183

184

185

186

187

Jonason,P.K.,Koenig,B.L.,\&Tost,J.(2010). Living a fast life. Human Nature, 21, 428-442.

Jonason,P.K.,Li,N.P.,\&Teicher,E.A.(2010). “Who is James Bond?: The dark triad as an agentic social style": Erratum. Individual Differences Research,8.

Jonason,P.K., \& Schmitt,D.P.(2012). What have you done for me lately? Friendship-selection in the shadow of the dark triad traits. Evolutionary

Psychology,10,147470491201000300.doi:10.1177/147470491201000303

Jonason,P.K., \& Webster,G.D.(2012). A protean approach to social influence: Dark triad personalities and social influence tactics. Personality and Individual Differences,52,521526.doi:10.1016/j.paid.2011.11.023

Jones,D.N., \& Paulhus,D.L.(2013). Introducing the Short Dark Triad (SD3): A brief measure of dark personality traits. Assessment.doi:10.1177/1073191113514105

Kajonius,P.J.,Persson,B.N.,Rosenberg,P.,\&Garcia,D.(2016). The (mis)measurement of the Dark Triad Dirty Dozen: Exploitation at the core of the scale. PeerJ,4.doi:10.7717/peerj.1748

Kiire,S.(2017). Psychopathy rather than Machiavellianism or narcissism facilitates intimate partner violence via fast life strategy. Personality and Individual Differences, 104,401406.doi:10.1016/j.paid.2016.08.043

Kowalski,C.M.,Rogoza,R.,Vernon,P.A.,\&Schermer,J.A. (2018). The Dark Triad and the selfpresentation variables of socially desirable responding and self-monitoring. Personality and Individual Differences,120,234-237.doi:10.1016/j.paid.2017.09.007

McCullough,M.E.,Emmons,R.A.,Kilpatrick,S.D.,\&Larson,D.B.(2001). Is gratitude a moral affect? Psychological Bulletin,127,249-266.doi:10.1037/0033-2909.127.2.249 
188

189

190

191

192

193

194

195

196

197

198

199

200

201

202

203

204

205

206

McCullough,M.E.,Emmons,R.A.,\&Tsang,J.A.(2002). The grateful disposition: A conceptual and empirical topography.Journal of Personality and Social Psychology,82,112127.doi:10.1037//0022-3514.82.1.112

Miller,J.D.,Vize,C.,Crowe,M.L.,\&Lynam,D.R.(2019). A critical appraisal of the Dark-Triad literature and suggestions for moving forward.Current Directions in Psychological Science,28,353-360.doi:10.1177/0963721419838233

Paulhus,D.L.,\&Williams,K.M.(2002). The dark triad of personality: Narcissism, Machiavellianism, and psychopathy. Journal of Research in Personality,36,556563.doi:10.1016/S0092-6566(02)00505-6

Rauthmann,J.F.,\& Kolar,G.P.(2013). Positioning the Dark Triad in the interpersonal circumplex: The friendly-dominant narcissist, hostile-submissive Machiavellian, and hostiledominant psychopath? Personality and Individual Differences,54,622627.doi:10.1016/j.paid.2012.11.021

Wood,A.M.,Maltby,J.,Stewart,N.,Linley,P.A.,\& Joseph,S.(2008). A social-cognitive model of trait and state levels of gratitude.Emotion,8,281-290.doi:10.1037/1528-3542.8.2.281

Zhao,K.,Ferguson,E.,\& Smillie,L.D.(2016). Prosocial personality traits differentially predict egalitarianism, generosity, and reciprocity in economic games. Frontiers in Psychology,7,1137.doi:10.3389/fpsyg.2016.01137 
Table 1

208

\begin{tabular}{|c|c|c|c|c|c|c|c|c|c|c|c|c|c|c|c|}
\hline & $M$ & $S D$ & 1 & 2 & 3 & 4 & 5 & 6 & 7 & 8 & 9 & 10 & 11 & 12 & 13 \\
\hline 1. Age & 23.37 & 8.04 & 1 & & & & & & & & & & & & \\
\hline 2. Sex & 1.25 & 0.45 & -0.02 & 1 & & & & & & & & & & & \\
\hline 3. Nationality & 1.66 & 0.69 & $-0.11^{* *}$ & 0.07 & 1 & & & & & & & & & & \\
\hline 4. Self-Deceptive & 30.44 & 7.48 & $0.16^{* * *}$ & 0.03 & -0.02 & 1 & & & & & & & & & \\
\hline \multicolumn{16}{|l|}{ Enhancement } \\
\hline 5. Impression & 34.10 & 8.16 & $0.21^{* * *}$ & $-0.13^{* *}$ & -0.05 & $0.37^{* * * *}$ & 1 & & & & & & & & \\
\hline \multicolumn{16}{|l|}{ Management } \\
\hline 6. Social & 64.53 & 12.94 & $0.22^{* * *}$ & -0.06 & -0.04 & $0.81^{* * *}$ & $0.84^{* * * *}$ & 1 & & & & & & & \\
\hline \multicolumn{16}{|l|}{ Desirability } \\
\hline 7. & 26.35 & 6.25 & $-0.21^{* * *}$ & $0.24^{* * *}$ & $0.08^{*}$ & -0.06 & $-0.42^{* * *}$ & $-0.30^{* * * *}$ & 1 & & & & & & \\
\hline \multicolumn{16}{|l|}{ Machiavellianism } \\
\hline 8. Narcissism & 25.09 & 4.62 & $-0.10^{* *}$ & 0.01 & -0.06 & $0.19^{* * *}$ & $-0.08^{*}$ & 0.06 & $0.30^{* * *}$ & 1 & & & & & \\
\hline 9. Psychopathy & 18.39 & 5.42 & $-0.18^{* * *}$ & $0.24^{* * * *}$ & $0.15^{* * *}$ & -0.05 & $-0.41^{* * *}$ & $-0.29^{* * *}$ & $0.53^{* * *}$ & $0.30^{* * *}$ & 1 & & & & \\
\hline 10. Dark Triad & 69.84 & 12.57 & $-0.22^{* * *}$ & $0.23^{* * *}$ & $0.08^{*}$ & 0.02 & $-0.41^{* * *}$ & $-0.25^{* * *}$ & $0.84^{* * *}$ & $0.65^{* * *}$ & $0.81^{* * *}$ & 1 & & & \\
\hline 11. Trait Gratitude & 34.23 & 5.88 & $0.10^{* *}$ & $-0.13^{* * *}$ & $-0.17^{* * *}$ & $0.20^{* * *}$ & $0.22^{* * *}$ & $0.25^{* * *}$ & $-0.26^{* * *}$ & 0.04 & $-0.40^{* * *}$ & $-0.29^{* * * *}$ & 1 & & \\
\hline 12. Situation & 1.33 & 0.47 & 0.01 & -0.01 & -0.01 & $-0.13^{* * *}$ & -0.05 & $-0.11^{* *}$ & -0.03 & $-0.12^{* *}$ & 0 & -0.06 & -0.07 & & \\
\hline 13. State & 14.19 & 3.29 & 0.06 & 0 & $-0.10^{* *}$ & $-0.09^{*}$ & 0.03 & -0.03 & -0.02 & $-0.08^{*}$ & -0.07 & -0.07 & $0.14^{* * *}$ & $0.61^{* * *}$ & 1 \\
\hline Gratitude & & & & & & & & & & & & & & & \\
\hline
\end{tabular}

Descriptive statistics and zero-order correlations between the variables. 